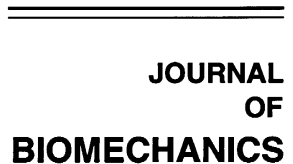

Journal of Biomechanics 34 (2001) 773-781

www.elsevier.com/locate/jbiomech www.JBiomech.com

\title{
Structural properties of a new design of composite replicate femurs and tibias
}

\author{
Anneliese D. Heiner ${ }^{\mathrm{a}, *}$, Thomas D. Brown ${ }^{\mathrm{a}, \mathrm{b}}$ \\ ${ }^{a}$ Department of Orthopaedic Surgery, University of Iowa, Iowa City, IA 52242, USA \\ ${ }^{\mathrm{b}}$ Department of Biomedical Engineering, University of Iowa, Iowa City, IA 52242, USA
}

Accepted 10 January 2001

\begin{abstract}
The purpose of this study was to compare the structural properties of a new vs. established design of composite replicate femurs and tibias. The new design has a cortical bone analog consisting of short-glass-fiber-reinforced (SGFR) epoxy, rather than the fiberglass-fabric-reinforced (FFR) epoxy in the currently available design. The hypothesis was that this new cortical bone analog would improve the uniformity of structural properties between specimens, while having mean stiffness values in the range of natural human bones. The composite replicate bones were tested under bending, axial, and torsional loads. In general, the new SGFR bones were significantly less stiff than the FFR bones, although both bone designs reasonably approximated the structural stiffnesses of natural human bones. With the exceptions of the FFR bone axial tests, the highest variability between specimens was $6.1 \%$. The new SGFR bones had similar variability in structural properties when compared to the FFR bones under bending and torsional loading, but had significantly less variability under axial loading. Differences in epiphyseal geometry between the FFR and SGFR bones, and subsequent seating in the testing fixtures, may account for some of the differences in structural properties; axial stiffness was especially dependent on bone alignment. Stiffness variabilities for the composite replicate bones were much smaller than those seen with natural human bones. Axial strain distribution along the proximal-medial SGFR femur had a similar shape to what was observed on natural human femurs by other investigators, but was considerably less stiff in the more proximal locations. (C) 2001 Elsevier Science Ltd. All rights reserved.
\end{abstract}

Keywords: Biomechanical model; Bone stiffness; Bone mechanics; Femur; Tibia

\section{Introduction}

Much ongoing research and development of orthopaedic devices is reliant on composite replicate femurs and tibias (Sawbones, Pacific Research Laboratories, Inc., Vashon, WA). Acknowledged advantages of these composite replicate bones over natural human bones are less inter-specimen variability, ready availability, and ease of handling; they also do not degrade (Cristofolini et al., 1996). The first mechanically realistic replicate femurs were introduced in 1987. These replicate bones had a cortical bone analog consisting of epoxy reinforced with a braided tube of glass fiber. This cortical bone analog had less than ideal bonding

*Corresponding author. Orthopaedic Biomechanics Laboratory, 2181 Westlawn Building, University of Iowa, Iowa City, IA 52242, USA. Tel.: + 1-319-335-7541; fax: +1-319-335-7530.

E-mail address: anneliese-heiner@uiowa.edu (A.D. Heiner). between the glass fiber and epoxy, because of the sizing on the glass, prompting the introduction of a subsequent generation of fiberglass-fabric-reinforced (FFR) composite replicate bones in 1991. However, the composite fiberglass laminates associated with these latter replicate bones require manual craftsmanship, and thus are less than ideal in terms of ease of manufacture, anatomic detail, and uniformity of mechanical properties both within a given specimen and between specimens (Pacific Research Laboratories, personal communication). For that reason, use of a short-glass-fiber-reinforced (SGFR) epoxy for the cortical material of the composite replicate bones was explored. This SGFR cortical material has a tensile modulus of $19 \mathrm{GPa}$, as tested by the authors according to ASTM D638-91 (with a modified strain rate of $15.2 \mathrm{~cm} / \mathrm{min}$ ). This new cortical analog offered the possibility of improving the uniformity of mechanical properties within a composite replicate bone, allowed for greater anatomic detail to be 
added to the bones, and simplified the fabrication process (Pacific Research Laboratories, personal communication).

To be an adequate experimental vehicle, composite replicate bones need to be structurally (and geometrically) equivalent to natural bones. Cristofolini et al. (1996) and Cristofolini and Viceconti (2000) tested FFR composite replicate femurs and tibias, respectively as regards structural equivalence with natural human bones. They measured axial, bending and torsional stiffness of the composite and natural human bones, and determined strain distribution in the proximal femur. For the femur, they found the stiffnesses of the composite bones were within the range of natural human bones. For the tibia, they found that bending stiffnesses of composite bones were within the range of natural human bones; however, torsional stiffness was much higher for the composite bones (axial stiffness data were not reported because of reproducibility problems). Additionally, for both the femurs and tibias, they found that inter-specimen variability was much smaller for the composite bones than for natural human bones. It is important, obviously, to characterize the new SGFR composite replicate bones, to ensure that after design and material changes they remain an adequate experimental vehicle. The hypothesis for the present study was that, compared to the established
FFR embodiment, the new SGFR cortical analog would improve the uniformity of structural properties between composite replicate bones, while having mean stiffness values in the range of natural human bones.

\section{Methods}

Six FFR composite femurs, six SGFR composite femurs, six FFR composite tibias, and six SGFR composite tibias (model numbers 3106 and 3104 for the femurs and tibias, respectively; Pacific Research Laboratories, Inc., Vashon, WA) (Fig. 1) were tested. The geometries of the composite bones were based on bones from an $890 \mathrm{~N}$ (90.8 kgf), $183 \mathrm{~cm}$ tall male (left side); a mold was made from each cadaver bone and used to make the composite bones. The fabrication technique associated with the new SGFR cortical analog allowed more geometric detail to be added to the bones, especially in the epiphyses. One of the reasons for this was associated with the smoothing out of the mold surface texture, which was necessary to allow the composite bone to release from the mold. For the FFR bones, the amount of smoothing necessary for mold release compromised the actual cadaver geometry, while for the SGFR bones, the amount of smoothing was very minor and did not noticeably compromise the
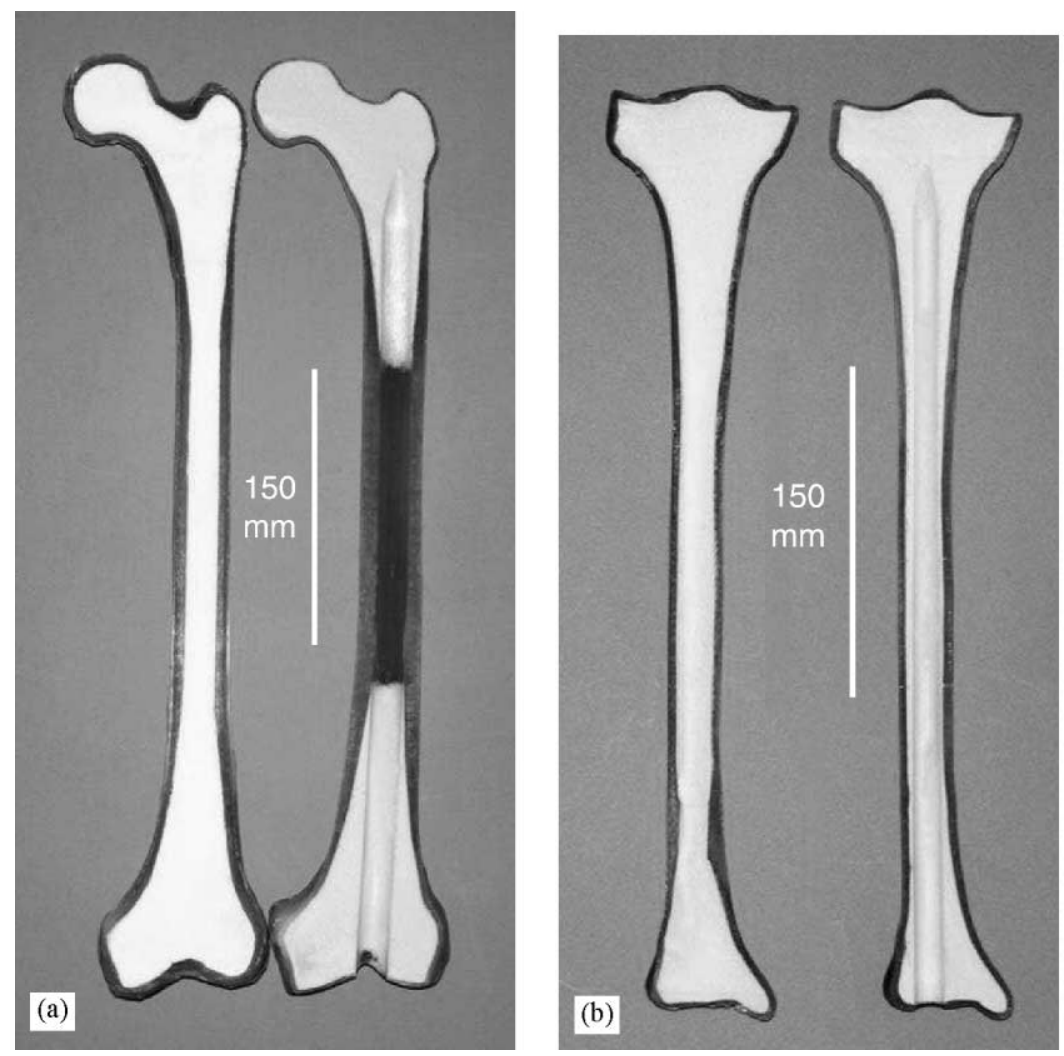

Fig. 1. Proximal cross-sections of (left) FFR and (right) SGFR composite replicate (a) femurs and (b) tibias. 
cadaver geometry. For the FFR femurs, the diaphyseal cross-sections were round; for the SGFR femurs, the diaphyseal cross-sections were more oval shaped and anatomically realistic, including the addition of a linea aspera. The cancellous analog material was identical in composition between the FFR and SGFR bones. However, for the FFR bones, the cancellous material filled the entire intramedullary space. The SGFR bones had a hollow intramedullary shaft (Fig. 1), with a diameter of 15.5 and $12.7 \mathrm{~mm}$ for the femurs and tibias respectively; the hollow shaft was added to increase anatomic realism and to decrease the difficulty of reaming.

Each composite replicate bone was tested under bending, axial, and torsional loading in an MTS 858 Bionix materials testing machine (MTS Systems Corp., Eden Prairie, MN). The research design used the FFR composite femur study of Cristofolini et al. (1996) as a guideline, but some modifications were made. Load and deflection data, or torque and rotation data, were measured and collected by the MTS system. The load/ deflection or torque/rotation slope was calculated by linear regression. For each type of bone and test, average, standard deviation, and coefficient of variation (COV, standard deviation/average) of the series were calculated. The results for the FFR and SGFR bones were statistically compared with the 2-tailed t-test (to compare means) and the F-test (to compare standard deviations) $(\alpha=0.05)$. For each type of bone and test, one specimen was completely re-tested (including repotting when applicable) to determine repeatability of the entire setup.

\subsection{Flexural rigidity}

Bending was applied through a 4-point bending fixture, with $62 \mathrm{~mm}$ between successive points. The longitudinal midstation of each bone was aligned at the center of the 4-point bending fixture. Each bone was bent in two directions, anterior surface in tension and lateral surface in tension; the exact directions were those for which the condyles were level horizontally or vertically, respectively. The femurs were constrained from axial rotation by a clamp located on the most distal support of the bending fixture (Fig. 2a). The tibias were constrained from axial rotation by low melting point alloy (Cerrobend, Cerro Metal Products Co., Bellefonte, PA) molds (one for each direction) that conformed to the bone surface, and were located on the most distal support of the bending fixture (Fig. 2b). (The tibias could not be held in place with a clamp; they slipped out of alignment as the clamp was tightened.)

The specimens were transversely loaded from 50 to $500 \mathrm{~N}$ at $0.025 \mathrm{~mm} / \mathrm{s}$. There was one preconditioning load cycle, followed by one data collection load cycle. This procedure was repeated 8 times for each specimen,
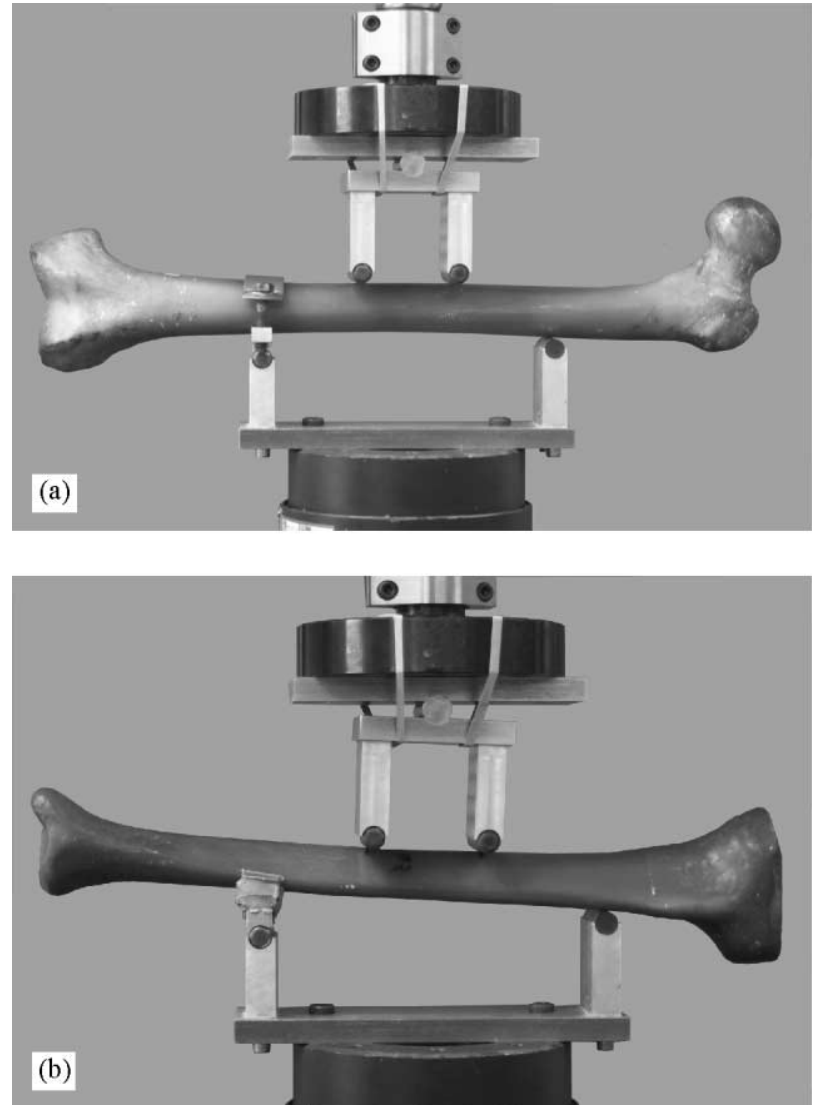

Fig. 2. Four-point bending of composite replicate (a) femur and (b) tibia.

removing and replacing the specimen each time. The load/deflection slope was converted to apparent flexural rigidity $(E I)$ by the equation:

$E I=\frac{5}{12} \frac{\lceil P\rceil}{\lfloor y\rfloor} c^{3}$,

where $E$ is the elastic modulus, $I$ the moment of inertia, $P / y$ the slope of the load-deflection curve, and $c$ the distance between inner and outer support.

\subsection{Axial stiffness}

The composite replicate femurs and tibias were distally potted with Cerrobend to depths of approximately 8.5 and $8 \mathrm{~cm}$, respectively. To obtain repeatable results, the bones were consistently oriented prior to the potting procedure by means of an alignment mold attached to the actuator of the MTS machine. Different molds were necessary for the FFR and SGFR designs of the same bone, because of geometric differences between the bone epiphyses. The femur molds held the femurs with the femoral shaft at $11^{\circ}$ from the vertical, in the direction of adduction, and conformed to the head, neck, and greater trochanter. The tibia molds held the tibias vertically, and conformed to the tibial condyles 


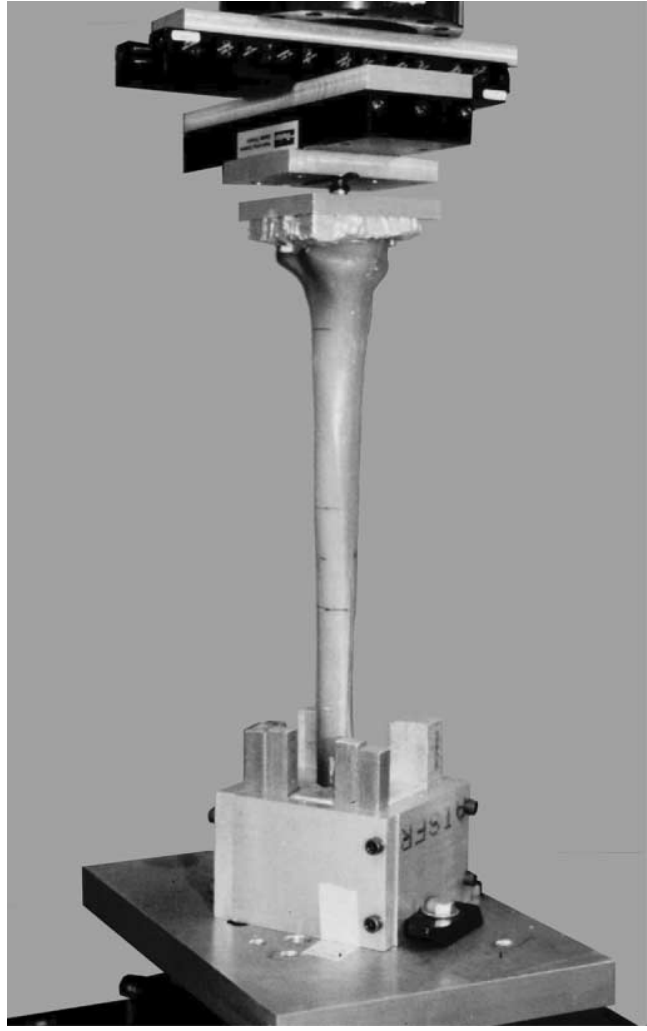

Fig. 3. Axial testing of composite replicate tibia.

(one SGFR tibia could not be tested, because an unidentified irregularity in the condyle kept this bone from aligning itself properly in the mold). The femurs and tibias were loaded through a platen that conformed to the femoral head or the tibial condyles, respectively. These load platens were connected to the MTS machine by a ball joint allowing free rotation, in series with a bearing support allowing free horizontal translation (Fig. 3).

The specimens were loaded from 60 to $600 \mathrm{~N}$ of compression at $60 \mathrm{~N} / \mathrm{s}$. There were two preconditioning load cycles, followed by one data collection load cycle. This procedure was repeated 8 times for each specimen, removing and replacing the load platen each time.

\subsection{Axial strain, femurs}

Strain distribution along the proximal-medial diaphysis was measured for three specimens of each of the two composite replicate femur designs. Five unidirectional strain gages (CEA-06-125UW-350, Measurements Group, Inc., Raleigh, NC) were applied on each specimen. The strain gages were equally spaced along the proximal-medial diaphysis, from the level of the lesser trochanter to the middle of the shaft (Fig. 4); these distances were the same for the FFR and SGFR femurs. The femurs, in the same setup as for the axial stiffness test, were loaded to $600 \mathrm{~N}$ of compression at $60 \mathrm{~N} / \mathrm{s}$, held

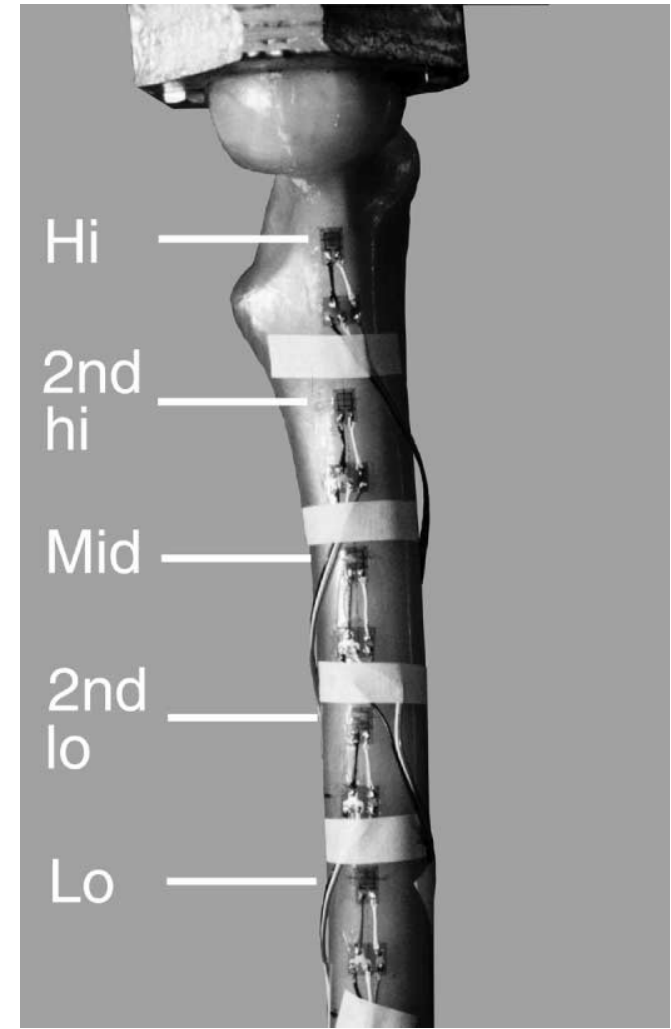

Fig. 4. Close-up of composite replicate femur strain gage placement.

at $600 \mathrm{~N}$ for $15 \mathrm{~min}$, unloaded to zero load at $60 \mathrm{~N} / \mathrm{s}$, then held at zero load for $15 \mathrm{~min}$. Strain and overall axial deflection were measured. The changes in strain and deflection from the start of the $15 \mathrm{~min}$ hold to the end of the $15 \mathrm{~min}$ hold at $600 \mathrm{~N}$ were calculated, as were the residual strains at 15 min after unloading.

\subsection{Torsional rigidity}

The composite replicate bones were proximally and distally potted with Cerrobend, leaving the middle $30.5 \mathrm{~cm}$ of the femurs free, and the middle $27.5 \mathrm{~cm}$ of the tibias free. The femurs were aligned prior to distal potting by means of an alignment mold attached to the actuator of the MTS machine. The molds held the femurs vertically, with their potted ends aligned with the torsional axis of the MTS machine, and conformed to the head, neck, and greater trochanter. The FFR tibias were aligned prior to distal potting by means of a mold attached to the actuator of the MTS machine. The tibia mold held the tibias vertically, and conformed to the condyles. The SGFR tibias were vertically aligned by means of an alignment rod prior to distal potting, to take advantage of the hollow intramedullary shaft that was not present in the FFR tibias (Fig. 1b). This rod was coincident with the torsional axis of the MTS machine; it came up through the loading plate and went up into 
the tibia's intramedullary shaft (the alignment rod depth was less than the potting depth, so the rod did not contribute to the torsional rigidity of the specimen).

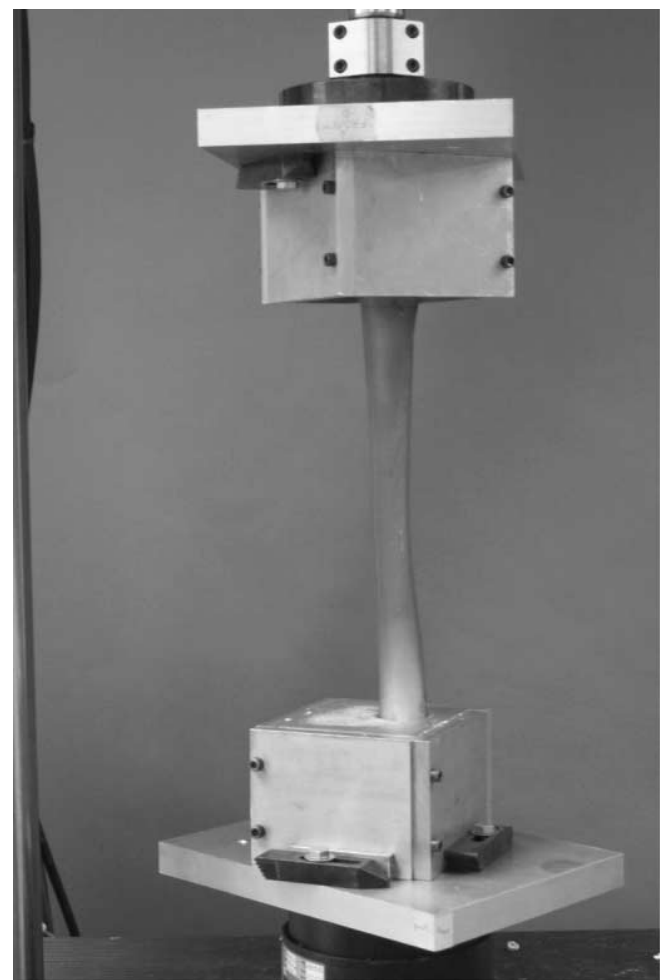

Fig. 5. Torsional testing of composite replicate femur.
Different molds were necessary for the FFR and SGFR femur designs, because of geometric differences between the bone epiphyses. The distally potted specimens were then turned upside down, attached to the MTS actuator, and potted proximally (Fig. 5). Both ends were constrained in all other motions except for axial displacement, which was allowed to "float" during the testing. Torsional loading was applied such that the proximal ends of the bones rotated internally.

The specimens were torqued from 0.5 to $15 \mathrm{Nm}$ at $0.25^{\circ} / \mathrm{s}$. There was one preconditioning torque cycle, followed by one data collection load. This procedure was repeated 5 times for each specimen, removing and replacing the specimen each time. The torque/rotation slope was multiplied by specimen length to calculate torsional rigidity (Martens et al., 1980).

\section{Results and discussion}

For the most part, the new SGFR composite replicate bones were significantly less stiff $(p<0.05)$ than the FFR bones (Table 1). The exceptions were femur bending with the anterior direction in tension (no statistically significant difference), femur bending with the lateral direction in tension (SGFR femurs significantly stiffer), and femur axial stiffness (no statistically significant difference). For tibia bending with the lateral direction in tension, and for femur torsion, there was less than a

Table 1

(a) Structural properties and (b) differences between structural properties of FFR and SGFR composite replicate bones ${ }^{\mathrm{a}}$

(a) Structural properties of FFR and SGFR composite replicate bones

\begin{tabular}{|c|c|c|c|c|}
\hline Property & Design & $\begin{array}{l}\text { Femur } \\
\text { Avg (COV) }\end{array}$ & $\begin{array}{l}\text { Tibia } \\
\text { Avg (COV) }\end{array}$ & Units \\
\hline $\begin{array}{l}\text { Flexural } \\
\quad \text { Rigidity, AT }\end{array}$ & $\begin{array}{l}\text { FFR } \\
\text { SGFR }\end{array}$ & $\begin{array}{l}294(5.1 \%) \\
290(3.1 \%)\end{array}$ & $\begin{array}{l}224(3.0 \%) \\
180(6.1 \%)\end{array}$ & $\mathrm{Nm}^{2}$ \\
\hline $\begin{array}{l}\text { Flexural } \\
\quad \text { Rigidity, LT }\end{array}$ & $\begin{array}{l}\text { FFR } \\
\text { SGFR }\end{array}$ & $\begin{array}{l}275(3.8 \%) \\
332(2.6 \%)\end{array}$ & $\begin{array}{l}177(4.2 \%) \\
162(4.7 \%)\end{array}$ & $\mathrm{Nm}^{2}$ \\
\hline $\begin{array}{l}\text { Axial } \\
\text { Stiffness }\end{array}$ & $\begin{array}{l}\text { FFR } \\
\text { SGFR }\end{array}$ & $1.90(13.3 \%)$ & $9.59(11.1 \%)$ & $\mathrm{N} / \mathrm{m}$ \\
\hline $\begin{array}{l}\text { Stiffness } \\
\text { Torsional }\end{array}$ & $\begin{array}{l}\text { SGFR } \\
\text { FFR }\end{array}$ & $\begin{array}{l}1.64(2.7 \%) \\
4.72(3.2 \%)\end{array}$ & $3.77(3.6 \%)$ & $\mathrm{Nm}^{2} / \mathrm{deg}$ \\
\hline Rigidity & SGFR & $4.27(5.2 \%)$ & $2.32(3.1 \%)$ & \\
\hline
\end{tabular}

(b) Differences between structural properties of FFR and SGFR composite replicate bones

\begin{tabular}{lllll}
\hline Specimen & Property & (SGFR-FFR)/SGFR (\%) & $P$ & $F$ \\
\hline Femur & Flexural rigidity, AT & -1 & 0.623 & $2 \times 10^{-6}$ \\
& Flexural rigidity, LT & +21 & 0.052 & 0.150 \\
& Axial stiffness & -14 & 0.005 & 0.353 \\
Tibia & Torsional rigidity & -9 & -19 & $3 \times 10^{-5}$ \\
& Flexural rigidity, AT & -8 & 0.006 & 0.001 \\
& Flexural rigidity, LT & -24 & 0.002 & 0.154 \\
& Axial stiffness & -38 & $2 \times 10^{-8}$ & 0.475 \\
\hline
\end{tabular}

\footnotetext{
${ }^{\text {a }} \mathrm{AT}=$ anterior surface in tension; LT $=$ lateral surface in tension. The SGFR tibias had $n=5$ for axial stiffness; otherwise, $n=6$. The $P$-value indicates the significance of the difference between the means, while the $F$-value indicates the significance of the difference between the standard deviations.
} 
Table 2

Structural properties of natural human and composite replicate bones ${ }^{\mathrm{a}}$

\begin{tabular}{|c|c|c|c|c|c|c|}
\hline Loading & Units & Specimen type & Mean & $\operatorname{COV}(\%)$ & $n$ & Reference \\
\hline \multicolumn{7}{|l|}{ (a) Femurs } \\
\hline \multirow[t]{5}{*}{ Bending, AT } & \multirow[t]{5}{*}{$\mathrm{Nm}^{2}$} & FFR & 271 & 8.2 & 4 & Cristofolini et al. (1996) \\
\hline & & SGFR & 290 & 3.1 & 6 & Present study \\
\hline & & FFR & 294 & 5.1 & 6 & Present study \\
\hline & & Natural & 305 & $\mathrm{~N} / \mathrm{A}$ & $\mathrm{N} / \mathrm{A}$ & Motoshima (1960) \\
\hline & & Natural & 369 & 42.7 & 4 & Cristofolini et al. (1996) \\
\hline \multirow[t]{5}{*}{ Bending, LT } & \multirow[t]{5}{*}{$\mathrm{Nm}^{2}$} & FFR & 248 & 2.5 & 4 & Cristofolini et al. (1996) \\
\hline & & FFR & 275 & 3.8 & 6 & Present study \\
\hline & & Natural & 277 & 29.2 & 4 & Cristofolini et al. (1996) \\
\hline & & Natural & 305 & $\mathrm{~N} / \mathrm{A}$ & $\mathrm{N} / \mathrm{A}$ & Motoshima (1960) \\
\hline & & SGFR & 332 & 2.6 & 6 & Present study \\
\hline \multirow[t]{3}{*}{ Axial } & \multirow[t]{3}{*}{$\mathrm{N} / \mathrm{mm}$} & FFR & 1370 & 4.5 & 8 & Cristofolini et al. (1996) \\
\hline & & SGFR & 1635 & 2.7 & 6 & Present study \\
\hline & & FFR & 1895 & 13.3 & 6 & Present study \\
\hline \multirow[t]{3}{*}{ Torsional } & \multirow[t]{3}{*}{$\mathrm{Nm}^{2} / \mathrm{deg}$} & Natural & 3.35 & 32.2 & 47 & Martens et al. (1980) \\
\hline & & SGFR & 4.27 & 5.2 & 6 & Present study \\
\hline & & FFR & 4.72 & 3.2 & 6 & Present study \\
\hline
\end{tabular}

(b) Tibias

\begin{tabular}{|c|c|c|c|c|c|c|}
\hline Bending, AT & $\mathrm{Nm}^{2}$ & SGFR & 180 & 6.1 & 6 & Present study \\
\hline \multirow[t]{2}{*}{$(\mathrm{PT})$} & & FFR & 213 & 8.4 & 8 & Cristofolini and Viceconti (2000) \\
\hline & & Natural & 215 & $\mathrm{~N} / \mathrm{A}$ & $\mathrm{N} / \mathrm{A}$ & Motoshima (1960) \\
\hline \multirow[t]{2}{*}{$(\mathrm{PT})$} & & Natural & 217 & 43.9 & 8 & Cristofolini and Viceconti (2000) \\
\hline & & FFR & 224 & 3.0 & 6 & Present study \\
\hline \multirow[t]{5}{*}{ Bending, LT } & $\mathrm{Nm}^{2}$ & FFR & 144 & 5.7 & 8 & Cristofolini and Viceconti (2000) \\
\hline & & SGFR & 162 & 4.7 & 6 & Present study \\
\hline & & FFR & 177 & 4.2 & 6 & Present study \\
\hline & & Natural & 182 & $\mathrm{~N} / \mathrm{A}$ & $\mathrm{N} / \mathrm{A}$ & Motoshima (1960) \\
\hline & & Natural & 193 & 58.0 & 8 & Cristofolini and Viceconti (2000) \\
\hline \multirow[t]{2}{*}{ Axial } & $\mathrm{N} / \mathrm{mm}$ & SGFR & 7304 & 5.5 & 5 & Present study \\
\hline & & FFR & 9589 & 11.1 & 6 & Present study \\
\hline \multirow[t]{3}{*}{ Torsional } & $\mathrm{Nm}^{2} / \mathrm{deg}$ & Natural & 1.66 & 34 & 37 & Martens et al. (1980) \\
\hline & & SGFR & 2.32 & 3.1 & 6 & Present study \\
\hline & & FFR & 3.77 & 3.6 & 6 & Present study \\
\hline
\end{tabular}

${ }^{\mathrm{a}} \mathrm{AT}=$ anterior surface in tension; PT $=$ posterior surface in tension (for values from Cristofolini and Viceconti $(2000)$ ); $\mathrm{LT}=$ lateral surface in tension. The values from Cristofolini et al. (1996) and Cristofolini and Viceconti (2000) were obtained by measuring off bar graphs. The composite replicate bones used by Cristofolini et al. (1996) and Cristofolini and Viceconti (2000) were smaller models (\#3103 and \#3101 for the femur and tibia, respectively) than those used in the current study (all from Pacific Research Laboratories, Inc.).

$10 \%$ difference between the FFR and SGFR bone designs, even though those differences were statistically significant. The reason for the increase in apparent flexural rigidity for the SGFR femurs with the lateral direction in tension is diaphyseal geometry. The diaphysis of the FFR femurs had a round cross-section, with a $30 \mathrm{~mm}$ diameter and a $6 \mathrm{~mm}$ wall thickness, while the diaphysis of the SGFR femurs was oval-shaped (for more anatomic realism), with a major (medial-lateral) axis of 32 and $9 \mathrm{~mm}$ wall thickness. The structural stiffnesses of both designs of composite replicate bones reasonably approximated the structural stiffnesses of natural human bones measured in other studies (Table 2).

Inter-specimen variability was $3.0-13.3 \%$ for the FFR bones, and $2.6-6.1 \%$ for the SGFR bones (Table $1 \mathrm{~b}$ ).
With the exceptions of the FFR axial tests (tibias and femurs), the highest COV was $6.1 \%$. The variability between the FFR and SGFR bones was not significantly different for bending and torsional stiffness, but was significantly different for axial stiffness (femurs, $p=0.001$; tibias, $p=0.040)$, with SGFR bone variability being considerably lower (Table $1 \mathrm{~b}$ ). The COV's for the FFR and SGFR bones in the present study were similar to the COV's for the FFR bones studied by Cristofolini et al. (1996) and Cristofolini and Viceconti (2000), which ranged from $2.0 \%$ to $8.4 \%$ (their FFR bones were smaller than those used in the present study). Inter-specimen variability with the composite replicate bones was much less than the variability seen with natural human bones (Table 2). 
Repeatability of each setup, calculated as the percent change between a test and re-test on the same specimen (with re-potting, when applicable), ranged from $0.0 \%$ to $13.3 \%$ for the FFR bones, and from $0.5 \%$ to $7.8 \%$ for the SGFR bones. The only repeatability that was greater than $8 \%$ was for the FFR tibias in torsion, with a repeatability of $13.3 \%$ (despite an inter-specimen COV of $3.6 \%$ ). Intra-specimen variability between the 8,8 or 5 runs on each specimen (for bending, axial and torsional loading respectively) was low; the highest variability for all bones and all tests was $4.5 \%$.

Variation in stiffness results can come from two sources: intrinsic variation between the specimens, and variation in specimen alignment or positioning (King et al., 1993; Swiontkowski et al., 1987). To obtain repeatable and reproducible axial results, it was necessary to use alignment molds to consistently orient the replicate bones, rather than visually orienting them. In an early round of axial testing of the SGFR tibias, initial alignment was achieved by a centrally-located rod which went up into the tibia's intramedullary shaft, then fine alignment was achieved by visually aligning the specimen vertically (using an MTS column as a vertical reference). This technique resulted in a COV of $18 \%$. To improve this, in the next round of testing the tibias were aligned by means of a mold attached to the actuator of the MTS machine. This alignment technique reduced the $\mathrm{COV}$ to $5.5 \%$. Since the rod-alignment technique did work well for the SGFR tibia torsional results, with a COV of $3.1 \%$ (Table 1), the torsional tests were not repeated using the alignment mold.

The SGFR composite replicate bones had clearly superior geometric reproducibility. They all fit well into their axial and torsional molds, with the exception of one tibia. The proximal geometry of the FFR tibias, however, had slight differences between all specimens, especially at the intercondylar eminence. Even after ablating the alignment mold at this area, to attempt to accommodate these differences, a secondary, visual alignment technique still had to be used at the distal end. This is likely the cause of the significantly higher COV (11\%) for the FFR tibia axial stiffness (Table 1). A similar problem occurred for the FFR femurs. Those specimens had a slightly irregular narrow fissure between their anterior and posterior halves, a byproduct of the fabrication technique. This was accom- modated when casting the (proximal) alignment mold by placing multiple layers of masking tape over the specimen fissure, to build this area up and create a narrow trench in the alignment mold. Despite this, the COV for the FFR femur axial stiffness was still relatively high $(13 \%)$ (Table 1$)$. Torsional rigidity was not nearly as sensitive to exact alignment of the specimens as was axial stiffness.

Because of proximal geometry differences, the FFR and SGFR femurs were not aligned using the same femoral axial or torsional mold, and the FFR and SGFR tibias were not aligned using the same tibial axial or torsional mold. This has implications for the axial testing especially, since reproducible axial stiffness results were determined to be highly dependent on consistent specimen alignment. Cristofolini and Viceconti (2000) did not report axial stiffness data for FFR composite replicate tibias, owing to large data scatter resulting from bone alignment problems.

Compressive strain in the composite replicate femurs was the highest at the most proximal strain gage, and decreased for the more distal strain gage positions (Table 3, Fig. 6). After $15 \mathrm{~min}$ at $600 \mathrm{~N}$ of compression, the average and maximum increases in compressive strain (for all strain gage positions) were $2.0 \%$ and $3.5 \%$ for the FFR femurs, and $4.8 \%$ and $9.8 \%$ for the SGFR femurs. At $15 \mathrm{~min}$ after unloading, the residual strains averaged $4 \mu \varepsilon$, and ranged from -10 to $+21 \mu \varepsilon$. The average and maximum relative increases in overall femur deflection after $15 \mathrm{~min}$ at $600 \mathrm{~N}$ of compression were $2.2 \%$ and $2.4 \%$ for the FFR femurs, and $0.5 \%$ and $0.9 \%$ for the SGFR femurs.

At or near the level of the lesser trochanter, the FFR femurs had a similar compressive strain to those reported for natural human femurs by other investigators, while the SGFR femurs had a higher compressive strain (Table 4a). Planned redesign of the SGFR femurs by the vendor includes increasing wall thickness in this area, to stiffen the specimen. At the level of a femoral prosthesis stem tip, both the FFR and SGFR femurs had compressive strains similar to values reported for natural human femurs by other investigators (Table $4 \mathrm{~b}$ ).

The axial strain distribution along the proximalmedial aspect of the SGFR femur had a similar shape to what was observed along natural human femurs tested in a similar manner by other investigators (Cristofolini

Table 3

Strain on FFR and SGFR composite replicate femoral proximal-medial shafts $(n=3)$, at $600 \mathrm{~N}$ of compression. Strain gages were equally spaced from the level of the lesser trochanter ("Hi") to the middle of the shaft ("Lo") (Fig. 4)

\begin{tabular}{llr}
\hline Strain gage location & FFR Avg $(\mathrm{COV})$ & SGFR Avg (COV) \\
\hline Hi & $-649(17 \%)$ & $-1225(5.7 \%)$ \\
2nd hi & $-545(7.3 \%)$ & $-797(1.1 \%)$ \\
Mid & $-536(3.2 \%)$ & $-543(5.9 \%)$ \\
2nd lo & $-420(9.0 \%)$ & $-389(1.0 \%)$ \\
Lo & $-297(20 \%)$ & $-207(5.3 \%)$ \\
\hline
\end{tabular}


Table 4

Strains on natural human and composite replicate femoral proximal-medial shaft (a) at or near the level of the lesser trochanter, and (b) at the level of a femoral prosthesis stem tip. Studies from which values were obtained were those which tested femurs in a manner similar to the present study-no muscle forces applied, no flexion/extension, and adduction angle limited to $9-15^{\circ}$. The composite replicate bones used by Cristofolini et al. (1996) and Cristofolini and Viceconti (2000) were smaller models (\#3103 and \#3101 for the femur and tibia, respectively) than those used in the current study (all from Pacific Research Laboratories, Inc.). The model number (indicating size) of the composite replicate femurs used by Otani et al. (1993b) was not specified. Strain gage locations were not exactly the same between the studies. Strains were normalized to a compressive load of $600 \mathrm{~N}$. When necessary, strain values were obtained by manually measuring off data plots

\begin{tabular}{llllll}
\hline $\begin{array}{l}\text { Specimen } \\
\text { Type }\end{array}$ & $\begin{array}{l}\text { Gage } \\
\text { designation }\end{array}$ & $\begin{array}{l}\text { Microstrain } \\
0600 \mathrm{~N}\end{array}$ & S.d. & $\begin{array}{l}\text { Adduction } \\
\text { angle }\end{array}$ & $N$ \\
\hline
\end{tabular}

(a) Gage height at or near the level of the lesser trochanter

$\begin{array}{llrrrrl}\text { Natural } & \text { Neck area } & -545 & -179 & 15 & 5 & \text { Oh and Harris, 1978 } \\ \text { FFR } & \text { L1 } & -622 & -89 & 9 & 3 & \text { Otani et al. (1993b) } \\ \text { FFR } & \text { Hi } & -649 & -110 & 11 & 1 & \text { Present study } \\ \text { Natural } & \text { M1 } & -654 & \text { N/A } & 11 & 14 & \text { Cristofolini et al. (1996) } \\ \text { Natural } & \text { Gauge } 5 & -682 & -220 & 10 & 1 & \text { Cristof et al. (1989) } \\ \text { FFR } & \text { M1 } & -698 & \text { N/A } & 11 & 21 & \text { Otani et al. (1993a) } \\ \text { Natural } & \text { Level-1 } & -748 & -122 & 9 & 3 & \text { Otani et al. (1993b) } \\ \text { Natural } & \text { L1 } & -794 & -107 & 9 & 5 & \text { Crowninshield et al. (1980) } \\ \text { Natural } & \text { PL } & -853 & -269 & 10 & 7 & \text { McBeath et al. (1980) } \\ \text { Natural } & \text { C } & -971 & -67 & 9 & 3 & \text { Present study }\end{array}$

(b) Gage height at the level of a femoral prosthesis stem tip

\begin{tabular}{|c|c|c|c|c|c|c|}
\hline Natural & Level-3 & -240 & -49 & 9 & 21 & Otani et al. (1993a) \\
\hline Natural & L3 & -241 & -52 & 9 & 3 & Otani et al. (1993b) \\
\hline Natural & M4 & -294 & $\mathrm{~N} / \mathrm{A}$ & 11 & 1 & Cristofolini et al. (1996) \\
\hline Natural & Stem tip & -381 & -163 & 15 & 5 & Oh and Harris, 1978 \\
\hline FFR & M4 & -414 & $\mathrm{~N} / \mathrm{A}$ & 11 & 1 & Cristofolini et al. (1996) \\
\hline FFR & Mid & -536 & -17 & 11 & 3 & Present study \\
\hline Natural & A & -620 & -162 & 9 & 7 & McBeath et al. (1980) \\
\hline
\end{tabular}

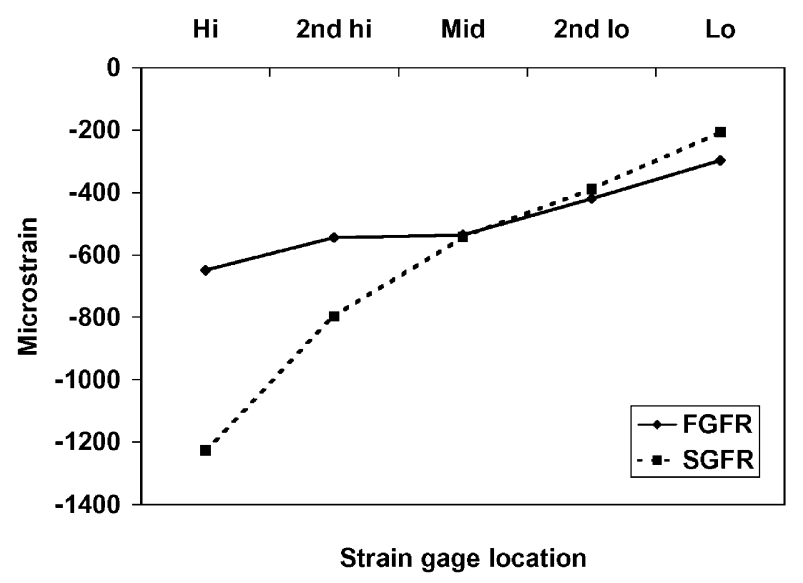

Fig. 6. Strain distribution on FFR and SGFR composite replicate femoral proximal-medial shafts. The shafts were tilted $11^{\circ}$ from the vertical. Strain gages were equally spaced from the level of the lesser trochanter ("Hi") to the middle of the shaft ("Lo").

et al., 1996; Crowninshield et al., 1980; Diegel et al., 1989; McBeath et al., 1980; Oh and Harris, 1978; Otani et al., 1993a; Otani et al., 1993b). For the SGFR femurs, and the natural human femurs, compressive strain decreased steadily as the position moved distally. However, for the FFR femurs, in both the current study and Cristofolini et al.'s study (1996), there was an irregularity in axial strain distribution - an increase in compressive strain between the 2nd and 3rd most proximal strain gages (Fig. 6).

\section{Conclusion}

Composite replicate bones with a SGFR cortical analog are being developed to improve upon currently available composite replicate bones fabricated with a FFR cortical analog. Advantages of using an SGFR cortical analog are that it offered the possibility of improving the uniformity of mechanical properties within a composite bone, allowed for greater anatomic detail to be included, and simplified the fabrication process. The new SGFR bones were hypothesized to have more uniform structural properties between specimens (when compared to FFR bones), and to have 
mean stiffness values in the range of natural human bones. The SGFR bones had similar variability in structural properties when compared to FFR bones under bending and torsional loading, and lower variability under axial loading (likely due to less alignment difficulty with the SGFR bones). Inter-specimen variability for both designs of composite bones was less than for corresponding natural human bones. The mean stiffness values for the FFR and SGFR composite replicate bones were consistent with stiffness values from natural human bones. However, the SGFR bones were in general significantly less stiff than the FFR bones; this included a high value of compressive strain measured on the proximal-medial femur at the level of the lesser trochanter. The SGFR bones are planned to be redesigned accordingly (Pacific Research Laboratories, personal communication).

\section{Acknowledgements}

The authors wish to thank Mr. Christopher L. Hruska for technical assistance. Pacific Research Laboratories, Inc. provided the funding.

\section{References}

Cristofolini, L., Viceconti, M., 2000. Mechanical validation of whole bone composite tibia models. Journal of Biomechanics 33 (3), 279288.

Cristofolini, L., Viceconti, M., Cappello, A., Toni, A., 1996. Mechanical validation of whole bone composite femur models. Journal of Biomechanics 29 (4), 525-535.
Crowninshield, R.D., Pedersen, D.R., Brand, R.A., 1980. A measurement of proximal femur strain with total hip arthroplasty. Journal of Biomechanical Engineering 102, 230-233.

Diegel, P.D., Daniels, A.U., Dunn, H.K., 1989. Initial effect of collarless stem stiffness on femoral bone strain. Journal of Arthroplasty 4, 173-178.

King, G.J.W., Glauser, S.J., Westreich, A., Morrey, B.F., An, K-N., 1993. In vitro stability of an unconstrained total elbow prosthesis. Journal of Arthroplasty 8 (3), 291-298.

Martens, M., Van Audekercke, R., De Meester, P., Mulier, J.C., 1980. The mechanical characteristics of the long bones of the lower extremity in torsional loading. Journal of Biomechanics 13, 667-676.

Martens, M., Van Audekercke, R., De Meester, P., Mulier, J.C., 1986. Mechanical behavior of femoral bones in bending loading. Journal of Biomechanics 19, 443-454.

McBeath, A.A., Schopler, S.A., Narechania, R.G., 1980. Circumferential and axial strain in the proximal femur: Effects of prosthesis type and position. Clinical Orthopaedics and Related Research 150, 301-305.

Motoshima, T., 1960. Studies on the strength of bending of human long extremity bones. Journal of Kyoto Prefectural University of Medicine 68, 1377-1397.

Oh, I., Harris, W.H., 1978. Proximal strain distribution in the loaded femur. Journal of Bone and Joint Surgery 60A, 75-85.

Otani, T., Whiteside, L.A., White, S.E., 1993a. The effect of axial and torsional loading on strain distribution in the proximal femur as related to cementless total hip arthroplasty. Clinical Orthopaedics and Related Research 292, 376-383.

Otani, T., Whiteside, L.A., White, S.E., 1993b. Strain distribution in the proximal femur with flexible composite and metallic femoral components under axial and torsional loads. Journal of Biomedical Materials Research 27, 575-585.

Pacific Research Laboratories, personal communication (Forrest Miller).

Swiontkowski, M.F., Harrington, R.M., Keller, T.S., Van Patten, P.K., 1987. Torsion and bending analysis of internal fixation techniques for femoral neck fractures: The role of implant design and bone density. Journal of Orthopaedic Research 5, 443-444. 